\title{
Explanatory factors of student performance in online tests for the continuous assessment: Is attendance really important?
}

Merello, Paloma ${ }^{\mathrm{a}}$ and Zorio-Grima, Ana ${ }^{\mathrm{a}}$

${ }^{\mathrm{a}}$ Department of Accounting, University of Valencia, Spain.

\begin{abstract}
In the European Higher Education Area, the educational model focuses on the student and the role of Information and Communication Technologies is crucial for the learning and teaching process. This study identifies the characteristics of the students according to their performance in the online tests carried out in a subject of Financial Accounting in the groups taught in English of the Degrees of Business Administration and Economics in a University from $X X X$. The objectives of this study are to explore the determining factors for student performance in online tests. Several analyses are carried out for all the marks and for a separated sample considering only the tests where the mark is at least good-i.e. the best or the second best grade in the national grading system. Among other intersting findings, our study evidences that attendance is a determining factor for the performance in each test if we take the whole group of students, but it is not significant for the students achieving better grades. This evidence has important implications as regards making attendance compulsory to benefit from the continuous assessment system.
\end{abstract}

Keywords: ICT; online tests, performance, Moodle. 


\section{Introduction}

Information and Communication Technologies (ICTs) are crucial for the learning and teaching process (UNESCO, 2008). In the European Higher Education Area (EHEA), the educational model focuses on the student (European Ministers of Education, 1999, Gonzalez, Arquero \& Hassall, 2009) so the changes implied by the EHEA promoted new teaching and assesment methodologies, taking advantage of ICT benefits in order to consider students' daily effort with different activities along the course (Segers and Doch, 2006). Rivero et al. (2017) find evidence that students achieve higher marks in coursework than in the final exam and that they perceive they gain deeper learning.

In the business field, a growing number of studies look into the introduction of ICT to promote new learning methodologies (see for instance Escobar-Rodriguez \& MongeLozano, 2012, on the acceptance of the Moodle platform). In the accounting field, Beltrá et al. (2011) and García-Benau \& Zorio-Grima (2012) propose the use of a mix of teaching methodologies including ICT's possibilities. Among these ICT activities, online questionnaires seem to be attractive both for the professor and the students, as it allows for easy self-correction for the former and formative assessment for the latter (Einig, 2013), increasing learning, motivation, and engagement (Marriott \& Lau, 2008, Marriott, 2009). However, some research shows that online questionnaires may lead to overconfidence, amongst certain type of students (Merello- Gimenez \& Zorio-Grima, 2017, Smolin \& Butakov, 2014).

As far we know, there is little research on the impact of determining factors on online questionnaires performance for the continuous assessment sytem, especially on attendance (Marriott \& Lau, 2008). Sometimes, class attendance is a component or even a requirement to benefit from the continuous assement system. Hence, the objective of this paper is to identify the factors leading to online test performance, in order to find valuable insights for the class attendance requirement debate in the continuous assessment system. The methodology employed in this study to obtain students performance is based on a set of Moodle online tests (Merello- Gimenez \& Zorio-Grima, 2017, Smolin \& Butakov, 2014, Marriott \& Lau, 2008, Marriott, 2009).

In fact, this paper makes a valuable contribution as evidence is found that attendance significantly improves online test performance for the whole group of students (which is consistent with Paisey \& Paisey, 2004), but it is not significant if we concentrate only on the best performing students in the online tests- which implies that the better students are able to catch up with the other students even if they missed the class. This suggests that considering class attendance as a requirement to benefit from the continuous assessment system favours the not so good students (because it promotes attendance), and may penalise the best students (who are able to catch up anyway). Our findings can be useful to justify 
that the continuous assessment system should require a specific level of attendance component if the online test performance drops below a certain grade (for instance the second best grade). That way, the not so good students are pushed to attend classes but the better students who are keeping a good online test performance do not get penalised if they miss a certain number of classes.

The rest of the paper unfolds as follows. After this introduction, we present the materials and methods, followed by the discussion of results. The paper closes with the conclusions section.

\section{Materials and Method}

\subsection{Teaching experience}

This teaching experience has been undertaken in two groups of Financial Accounting taught in English (which are expected to be "high performance groups") of the Business Administration Degree and the Economics Degree from University of Valencia with 29 and 62 students, respectively, taught in the summer semester. The data corresponds to year 2016/17 and to the continuous assessment system.

In the teaching process, the master class has been combined with different innovative teaching techniques, such as puzzle, role playing, videos, tasks, exercises, practical cases and online tests. However, in this study, we focus on students' performance just on the online tests (i.e., 5 tests in total, 1 test per chapter in the syllabus). These tests have been solved in the Moodle platform, combining true and false questions with multiple choice questions.

\subsection{Sample and Statistical analysis}

Different explanatory variables are used to explain students' performance in the online tests, including, attendance to class sessions (percentage), the difficulty of the contents analysed (as perceived by the student), the student's degree (Business Administration vs. Economics), the access mark to the university (from 0 to 14 points, being 14 the highest mark possible), the time of personal study before the online test, the studies of the parents, the gender and the age.

The complete sample has 455 observations (91 students x 5 tests). Only 364 cases are complete because some students do not follow the continuous assessment or do not take some of the tests. The descriptive characteristics of that sample are as follows: $55.5 \%$ are man (202 observations) and 44.5\% are woman (162); 91.5\% are less than 20 years old and 7.4\% are between 20-23 years old; regarding the access mark, 35.7\% obtained a mark between $8.5-10,51.1 \%$ a mark between 10 and 12 and $11 \%$ and access mark between 12 to 
14. Furthermore, $75.3 \%$ of the students' parents have University studies and only $3.8 \%$ have secondary studies or less.

In order to evaluate the differences between the students with the best results, a subsample is selected with those students with a mark which is at least good- i.e. the best or the second best grade in the national grading system. This subsample has 293 complete cases.

We use nonparametric techniques since the variables under study do not follow a normal distribution. Therefore, U-Mann Whitney analyses are performed for variables with two categories and Kruskal-Wallis for those variables with more than two categories. A significant Kruskal-Wallis test indicates that at least one sample stochastically dominates one other sample. This test allows us to decide if the hypothesis that the independent samples (categories of the categorical variables) come from the same population (or from identical populations with the same median) can be accepted. The necessary assumptions that the underlying distributions of the variables are continuous and that they have been measured at least on an ordinal scale, are satisfied by our variables.

\section{Results and discussion}

\subsection{Full sample of students}

Different tests are carried out to characterize the influence of determining factors on the mark obtained in the tests for the complete sample. It is controlled by the variable degree, since it could imply both differences in the students' groups and in the performance of the lecturer, although no significant differences are detected between both groups (Table 1).

Table 1. Results of the U-Mann Whitney and Kruskal-Wallis test for the complete sample.

\begin{tabular}{lccl}
\hline Variable & $\mathbf{z}$ /chi-square & $\mathbf{p}$-value & Test \\
\hline gender & -0.375 & 0,7070 & U-Mann Whitney \\
age & 6.364 & 0,0415 & Kruskal-Wallis \\
degree & -0.860 & 0,3899 & U-Mann Whitney \\
study time & 10.831 & 0,0285 & Kruskal-Wallis \\
test difficulty & 11.345 & 0,0229 & Kruskal-Wallis \\
Access mark & 14.691 & 0,0054 & Kruskal-Wallis \\
Parents' studies & 7.769 & 0.1004 & Kruskal-Wallis \\
\hline
\end{tabular}

The student's degree, gender and parents' studies are not significant according to the nonparametric contrasts performed. There are significant differences by age, where younger students (Figure 1.a) show greater variability in the marks.

The study time and the difficulty of the contents have a significant influence on the test mark. Thus, if the study time for the contents covered in a specific test is more than 5 hours 
(12 cases) a higher number of students achieve high marks in the tests (ranging from 8 to 10 points, Figure 1.b). There is no defined pattern for the remaining hours of study.

Regarding the difficulty of the chapter as perceived by the student, in those cases in which the perceived difficulty was very low marks are very high (Figure 1.c). Also, in the cases in which the perceived difficulty was very high the students always passed the test, probably due to an extra effort by the student.

In addition, the correlation between the attendance and the test scores with the nonparametric Spearman coefficient is checked. The correlation is significant (p-value = 0.029 ) and positive, although of low value (Spearman-rho $=0.114$ ).

a)

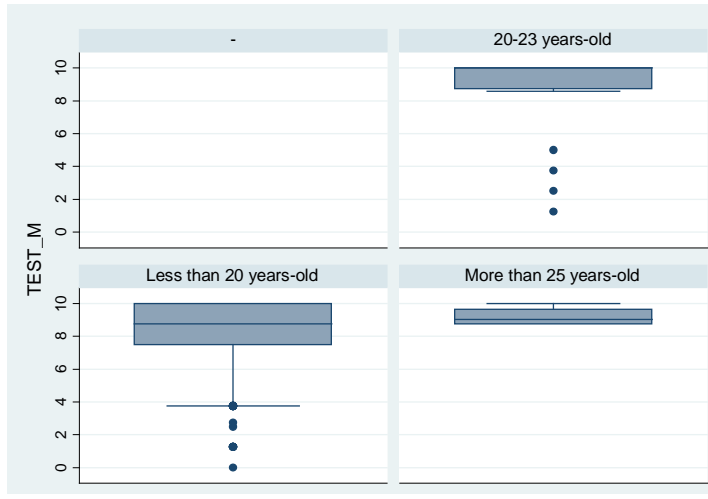

c)

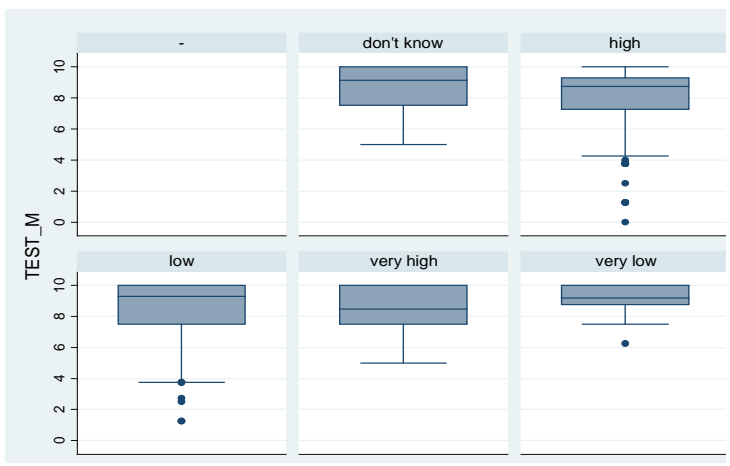

b)

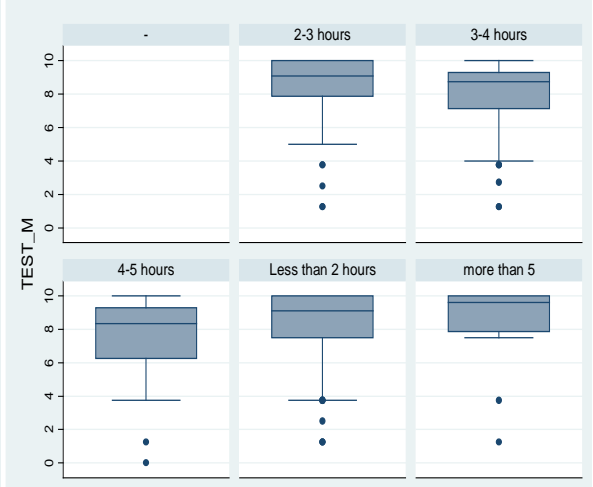

d)

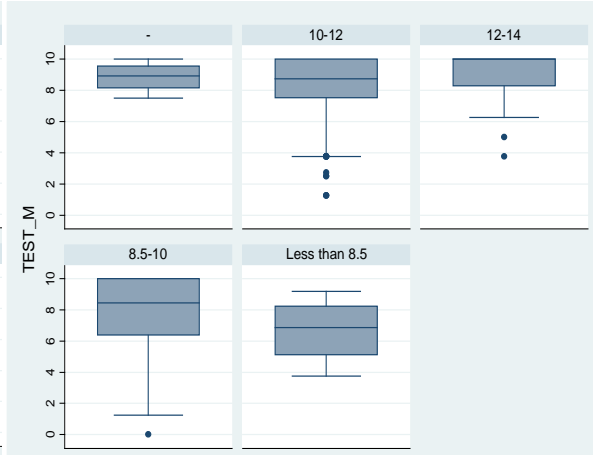

Figure 1. Box and whisker plots of the test mark variable for the categories of the significant variables: a) age, b) study time, c) difficulty and d) access mark.

\subsection{Best performance students}

Bearing in mind the fact that the best students could be expected to catch up with the other students even if they missed the class, we now concentrate on the sample of the students 
getting the best and secong best grade in the online tests (a mark ranging from 7 to 10 points). If we find differences regarding attendance as compared to the analysis above, conclusions might be drawn as regards considering the attendance requirement or component dependent on the test mark in order to benefit from the continuous assessment.

For the best performance students, there are no significant differences in terms of degree, access mark or gender (Table 2). Age follows a similar pattern as for the complete sample (Figure 2.a), where students over 20 years have less variability in the test marks.

Table 2. Results of the U-Mann Whitney and Kruskal-Wallis test for the best students.

\begin{tabular}{lccl}
\hline Variable & z /chi-square & p-value & Test \\
\hline gender & 0.468 & 0.6396 & U-Mann Whitney \\
age & 7.997 & 0.0183 & Kruskal-Wallis \\
degree & -0.843 & 0.3991 & U-Mann Whitney \\
study time & 12.669 & 0.0130 & Kruskal-Wallis \\
test difficulty & 13.736 & 0.0082 & Kruskal-Wallis \\
Access mark & 7.128 & 0.1293 & Kruskal-Wallis \\
Parents' studies & 9.843 & 0.0431 & Kruskal-Wallis \\
\hline
\end{tabular}

a)

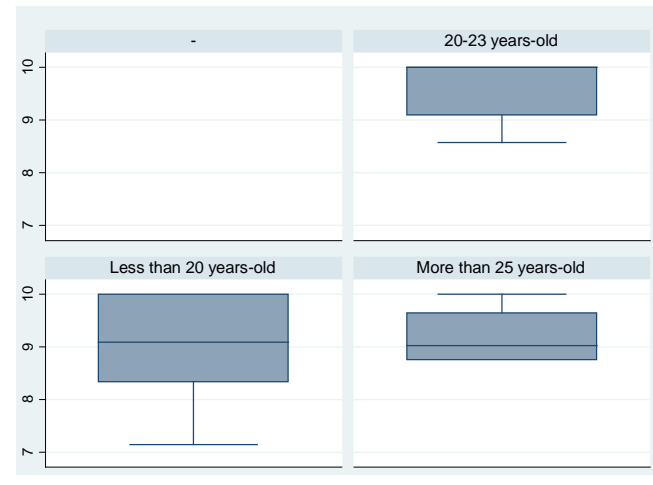

c) b)

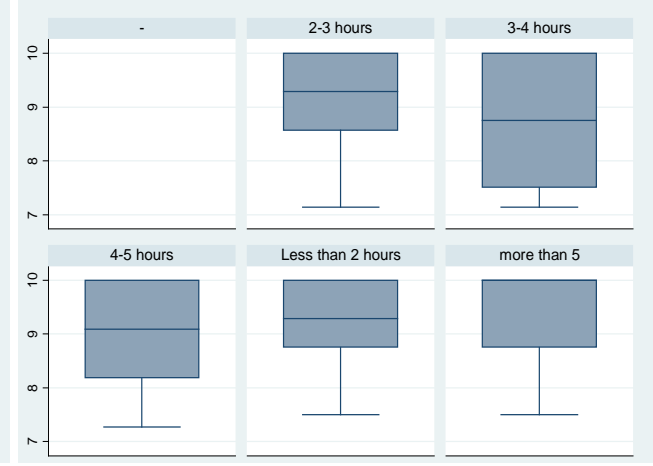

d) 

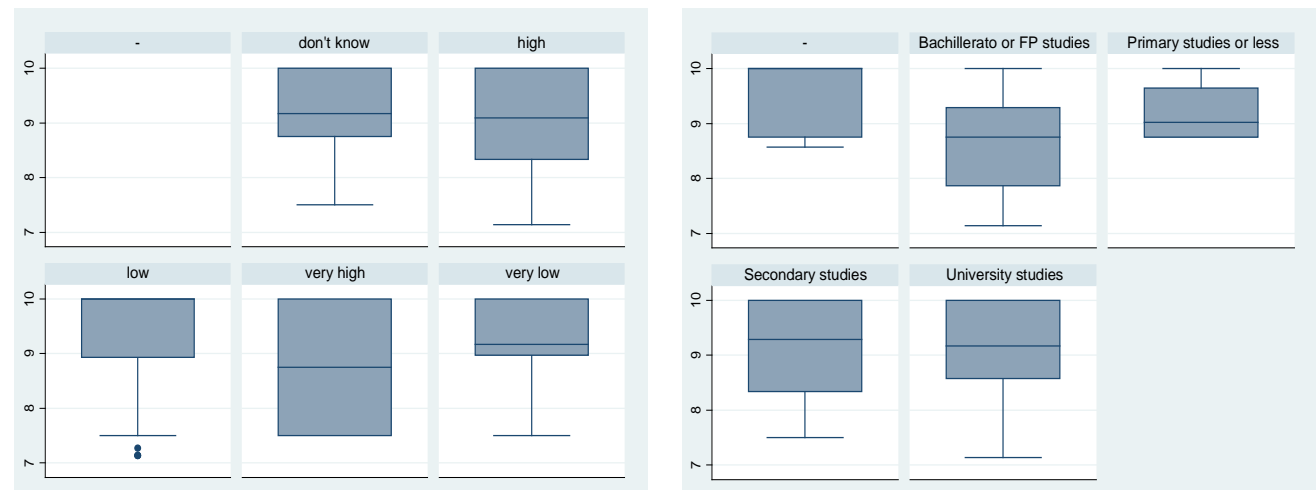

Figure 2. Box and whisker plots of the test mark variable for the categories of the significant variables: a) age, b) study time, c) difficulty and d) parents' studies.

In addition, the correlation between the attendance and the test scores is tested with the nonparametric Spearman coefficient resulting non-significant ( $\mathrm{p}$-value $=0.37$ ). This means that the attendance is decisive to pass the tests but that does not entail differences between the high marks.

\section{Conclusions}

The difficulty of the contents, the time of study, the access mark, age and attendance are determining factors of the mark in the online test for the whole group of students. However, in the case of students whose marks are the best and second grade, only the difficulty of the contents, the time of study, the studies of the parents and the age are significant. This makes us think about the different profile of the students in the classroom, although there are no differences between the degrees, nor the gender that is usually one of the determining variables in this type of studies (Merello- Gimenez \& Zorio-Grima, 2016).

Our study is specially valuable as regards the attendance factor. The evidence obtained suggests that considering class attendance as a requirement to benefit from the continuous assessment system favours the not so good students (because it promotes attendance), and may penalise the best students (who are able to catch up anyway). Our findings can be useful to justify that the continuous assessment system should require a specific level of attendance component if the online test performance drops below a certain grade (for instance the second best grade). That way, the not so good students are pushed to attend classes but the better students who are keeping a good online test performance do not get penalised if they miss a certain number of classes.

Future research might try to understand the better or worse performance of students if our recommendation above is implemented in a course. This type of studies can help planning 
better continuous assessment design and follow up of the students progress as the subject is being taught in the classroom.

\section{References}

Beltrá, J. L., Pereira, J. M., \& Sáez, J. L. (2011). Practical application of alternative teaching methods in Accounting. EDUCADE, The Spanish Journal of Accounting, Finance and Management Education, 2, 3-34.

Einig, S. (2013). Supporting Students' Learning: The Use of Formative Online Assessments. Accounting Education, 22(5), 425-444.

Escobar-Rodriguez, T., \& Monge-Lozano, P. (2012). The acceptance of Moodle technology by business administration students. Computers \& Education, 58(4), 1085 1093.

European Ministers of Education (1999). The Bologna Declaration of 19 June 1999 Joint declaration of the European Ministers of Education. Available at: http://media.ehea.info/file/Ministerial_conferences/02/8/1999_Bologna_Declaration_En glish_553028.pdf Accessed on 28/01/2018.

García-Benau, M. A., \& Zorio-Grima, A. (2012). Experience on the Use of a Mix of Teaching Methods in Higher Education of Accounting. Cuadernos de Contabilidad, 13(33), 613-657.

Marriott, P. (2009). Students' evaluation of the use of online summative assessment on an undergraduate financial accounting module. British Journal of Educational Technology, 40(2), 237-254.

Marriott, P., \& Lau, A. (2008). The use of on-line summative assessment in an undergraduate financial accounting course. Journal of Accounting Education, 26(2), 7390.

Merello-Giménez, P., \& Zorio-Grima, A. (2016). Moderating role of gender in the performance of Moodle questionnaires in an introductory Accounting course. Procedia - Social and Behavioral Sciences, 228, 407-412.

Merello-Giménez, P., \& Zorio-Grima, A. (2017). Impact of students’ performance in the continuous assessment methodology through Moodle on the final exam. EDUCADE, The Spanish Journal of Accounting, Finance and Management Education, 8, 57-68.

Paisey, C., \& Paisey, N. J. (2004). Student attendance in an accounting module-reasons for non-attendance and the effect on academic performance at a Scottish University. Accounting education, 13(sup1), 39-53.

Rivero, C. del Campo, C., Urquia-Grande, E., Camacho-Miñano, M.M., \& Pascual-Ezama, D. (2017) Analysing students' academic performance in Higher Education in Spain. EDUCADE, The Spanish Journal of Accounting, Finance and Management Education,, 8, 3-19

Segers, M. \& Dochy, F. (2006). Enhancing student learning through assessment: Alignment between levels of assessment and different effects on learning. Studies in Educational Evaluation, 32(3), 171-179. 
Smolin, D., \& Butakov, S. (2014). Resolving the Paradox of Overconfident Students with Intelligent Methods. In U. Kose, and D. Koc. (Eds.), Artificial Intelligence Applications in Distance Education (pp. 161-174). Hershey, USA: IGI Global.

UNESCO (2008). Estándares de competencias en TIC para docentes. Available at: http://www.oei.es/tic/UNESCOEstandaresDocentes.pdf. Accessed on the 27/01/2016 